\title{
Rancang Bangun Vibration Test Bench untuk Mensimulasikan Kondisi Unbalance dengan Pengaturan Putaran dan Beban Unbalance
}

\author{
Imam Maolana ${ }^{1}$ \\ ${ }^{1}$ Jurusan Teknik Mesin, Politeknik Negeri Indramayu, Jl. Lohbener Lama No. 8 Indramayu 45252 \\ E-mail : imam_malau@yahoo.com
}

\begin{abstract}
Abstrak
Penelitian ini bertujuan untuk merancang dan membuat vibration test bench guna mensimulasikan kondisi unbalance pada mesin rotasi. Vibration test bench yang dibuat terdiri dari sebuah poros baja diameter $25 \mathrm{~mm}$ dan panjang $410 \mathrm{~mm}$ yang ditopang oleh dua buah bantalan bola. Poros menyangga dua buah piringan massa unbalance yang berfungsi utuk memvariasikan beban unbalance. Poros diputar oleh motor listrik 0.5 PK, putaran maksimal 1400 RPM. Pengaturan putaran menggunakan inverter melalui pengaturan frekuensi listrik yang masuk ke motor listrik. Pengujian getaran dilakukan pada dua kondisi yaitu (1) kondisi tanpa beban dengan variasi putaran dan (2) kondisi beban massa unbalance dengan variasi massa unbalance. Pengukuran getaran dilakukan pada rumah bantalan arah radial (horisontal dan vertikal) serta aksial, parameter getaran yang diukur yaitu amplitudo dan spektrum getaran. Pengukuran amplitudo menggunakan hand held vibrometer, sedangkan pengukuran spektrum menggunakan Data Acquisition. Dari pengujian kondisi dengan beban unbalance bisa disimpulkan bahwa vibration test bench yang dibuat bisa menunjukan kondisi unbalance yaitu amplitudo tinggi pada 1X (satu kali) putaran mesin dan nilainya sebanding dengan massa unbalance. Dari penelitian juga diketahui bahwa amplitudo getaran paling besar pada arah horisontal dimana kekakuan mesin paling kecil. Dari pengujian kondisi tanpa beban dan dengan beban unbalance muncul 'harmonic' pada spektrum getaran yang merupakan ciri 'rotating looseness' kemungkinan diakibatkan oleh keausan bantalan.
\end{abstract}

Kata Kunci: vibration, vibration analysis, unbalance, vibration test bench, rotating looseness

\begin{abstract}
The goal of this work is to design and build a vibration test bench to simulate unbalance in rotating machine. The vibration test bench made of a $25 \mathrm{~mm}$ diameter steel shaft and length of $410 \mathrm{~mm}$ supported by two ball bearings. Two steel discs to variate unbalance load installed in the shaft powered by 0.5 Hp electric motor with maximum rotation of 1400 RPM. Inverter used to control rotation from electric motor. Vibration testing conducted at two condition; (1) without load and rotation variation, (2) unbalance load with variation of unbalance mass. Pick up point of vibration measurement at bearing house in radial and axial direction. The vibration parameter measured are amplitude and spectrum (wave form). Amplitude measurement using hand held vibrometer, while spectrum using accelerometer conected to a Data Acquisition. After testing the condition using unbalance load, we conclude that the vibration test bench match unbalance condition as described in theory which is high amplitude at machine frequency, and it's value proportional to unbalance mass. We find that the highest amplitude is at horizontal direction where machine stiffnes is smallest. Vibration testing with no load condition show that there is harmonic in vibration spectrum indicating rotating looseness, probably caused by bearing wear.
\end{abstract}

Keywords: vibration, vibration analysis, unbalance, vibration test bench, rotating looseness

\section{PENDAHULUAN}

Salah satu strategi perawatan mesin adalah perawatan prediktif (predictive maintenance), yang disebut juga condition based maintenance yaitu strategi perawatan mesin yang menggunakan perangkat monitoring kondisi (condition monitoring) untuk mendeteksi gejala kerusakan mesin dengan teknik tertentu tanpa menghentikan mesin. Kegiatan perbaikan dilakukan apabila dari hasil monitoring terdeteksi gejala kerusakan. Dengan penerapan strategi ini bisa mengurangi machine down time karena penghentian operasi mesin dilakukan pada saat yang diperlukan, biaya penggantian spare part juga bisa diminimalisir mengingat penggantian dilakukan pada saat yang dibutuhkan mesin sesuai hasil monitoring.

Ada beberapa teknik yang sudah secara umum digunakan dalam condition monitoring yaitu analisis getaran, emisi akustik (suara), termografi infrared, pengujian motor listrik, analisis minyak pelumas, dan analisis partikel keausan [1]. 
Monitoring (analisis) getaran adalah teknik yang paling umum digunakan sebagai bagian dari condition based maintenance, tidak hanya kalangan industri, instansi militer juga menerapkan teknik ini. Penerapannya mulai dari rotary machinery, engine pesawat, sampai mesin perkakas [2,3].

Vibration test bench adalah alat yang digunakan untuk menyelidiki getaran akibat beberapa kondisi kerusakan. Di Jurusan Teknik Mesin Politeknik Negeri Indramayu dimana salah satu bidang keahliannya adalah Perawatan dan Perbaikan Mesin, alat ini sangat diperlukan untuk penelitian monitoring kondisi mesin berbasis analisis getaran. Alat ini juga dibutuhkan sebagai media pembelajaran mata kuliah Teknik Monitoring Kondisi Mesin pada Program Studi D3 Teknik Mesin.

Tujuan penelitian ini adalah merancang dan membuat vibration test bench untuk mendeteksi unbalance.

\section{TINJAUAN PUSTAKA}

Menurut Mobley [4], perawatan prediktif adalah suatu teknik manajemen yang menggunakan evaluasi reguler dari kondisi operasi aktual suatu peralatan, sistem produksi, dan fungsi manajemen pabrik untuk mengoptimalkan operasi pabrik secara keseluruhan. Output dari program perawatan prediktif adalah data. Unjuk kerja pabrik tidak dapat ditingkatkan, sampai dilakukan tindak lanjut terhadap data penyimpangan atau persoalan yang ditemukan pada saat menjalankan program perawatan prediktif.

Condition based maintenance memerlukan penentuan dan peramalan (prognosis) kesehatan mesin secara tepat, disebut dengan monitoring kondisi (condition monitoring). Ada banyak teknik dan metode dalam monitoring kondisi mesin tergantung kepada sistem dan komponen yang akan dimonitor, yang secara umum dibagi menjadi offline dan online condition monitoring. Pada metode offline, monitoring dilakukan pada interval waktu tertentu. Sedangkan pada metode online, monitoring dilakukan terus menerus menggunakan sistem yang bisa secara otomatis memberikan laporan tentang parameter yang dimonitor bahkan memberikan peringatan (sebagai contoh alarm) [5].

Ada beberapa teknik yang sudah secara umum digunakan dalam condition monitoring yaitu analisis getaran, emisi akustik (suara), termografi infrared, pengujian motor listrik, analisis minyak pelumas, dan analisis partikel keausan. [1]

Monitoring getaran adalah perangkat perawatan prediktif yang mutlak diterapkan untuk setiap mesin-mesin rotating. Banyak program monitoring getaran pada berbagai industri yang telah mereduksi biaya dalam waktu kurang dari 1 tahun. [6]

Unbalance merupakan pola kerusakan yang paling sering terjadi pada peralatan mekanis. Faktanya, seluruh pola kerusakan akan menimbulkan beberapa bentuk unbalance pada mesin. [4]

Unbalance adalah kondisi dimana garis pusat poros tidak berhimpit dengan garis pusat massa. Dengan kata lain pusat massa tidak terdapat pada pusat putaran, atau adanya sebuah titik berat pada suatu tempat sepanjang poros. Titik berat ini akan menimbulkan gaya sentrifugal pada bantalan ketika poros berputar, dan gaya ini berbanding lurus dengan putaran poros. Unbalance akan mengakibatkan kerusakan sekunder berupa tegangan pada bantalan dan seal, mengeksitasi resonansi, dan menimbulkan kekendoran (looseness). Unbalance disebabkan oleh beberapa hal diantaranya kerusakan komponen, kerusakan akibat proses manufaktur, akumulasi partikel kotor, material tidak homogen, rotor eksentris, defleksi rotor, pemilihan pasak yang tidak tepat, dan lain-lain. [1]

Getaran akibat unbalance memiliki ciri utama yaitu amplitudo tinggi pada frekuensi $1 \mathrm{X}$ (satu kali) putaran poros akibat gaya sentrifugal dari massa unbalance. Sinyal getaran mesin yang mengalami unbalance akan menghasilkan bentuk gelombang sinusoidal. $[1,4,6]$

Vibration Test Bench merupakan perangkat riset dasar dalam monitoring kondisi mesin berbasis analisis getaran. Alat ini juga digunakan untuk media pembelajaran monitoring getaran mesin. Mevel \& Guyader [7] menggunakan vibration test bench yang terdiri dari komponen motor listrik dengan kontrol pengaturan frekuensi, poros, transmisi sabuk, bantalan, dan massa overhung untuk menyelidiki perkembangan kerusakan bantalan gelinding. Chen dkk [8] menyelidiki kerusakan pada gearbox dengan memanfaatkan vibration test bench yang terdiri dari komponen motor listrik, poros, sabuk gigi, kopling, bantalan, dan gearbox. Ghafari [9] mengembangkan sistem diagnosis kerusakan untuk mesinmesin rotating yang di-support oleh bantalan gelinding.

\section{METODE}

\subsection{Konsep Rancangan}

Konsep rencangan alat ditunjukan GAMBAR 1.



Gambar 1. Konsep rancangan 


\subsection{Pembuatan}

Pembuatan dilakukan di Laboratorium Teknologi Mekanik, Jurusan Teknik Mesin, Politeknik Indramayu.

\subsection{Pengujian}

Pengujian getaran dilakukan dengan pengukuran getaran rumah bantalan pada arah radial (horisontal dan vertikal) serta aksial. Pengukuran dilakukan pada:

- Kondisi tanpa beban, yaitu pada kondisi massa unbalance dan massa overhang tidak terpasang, hanya poros yang diputar oleh motor. Pada kondisi ini akan divariasikan putaran.

- Kondisi beban massa unbalance di tengah dengan variasi massa unbalance, dan putaran tetap.

Pada masing-masing kondisi di atas, parameter getaran yang diukur yaitu nilai amplitudo overall vibration dan spektrum getaran. Nilai amplitudo akan dibandingkan dengan standar getaran mekanis ISO 10816. Pengukuran overall vibration getaran menggunakan handheld vibrometer. Pengukuran spektrum menggunakan Data Acquisition (DAQ), pengolahan hasilnya menggunakan aplikasi MATLAB. Pengukuran spektrum dilakukan hanya pada arah horisontal, yang memiliki getaran paling besar mengingat alat ini memiliki kekakuan (stiffness) yang lebih kecil pada arah horisontal.

\section{HASIL DAN PEMBAHASAN}

Alat yang dibuat ditunjukan GAMBAR 2.

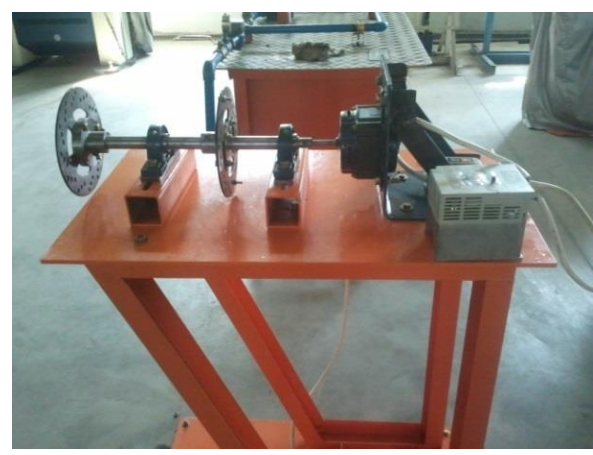

Gambar 2. Vibration test bench untuk mendeteksi unbalance

Spesifikasi vibration test bench adalah sebagai berikut:

- Motor listrik 0.5 PK putaran maksimal 1400 RPM

- Poros baja ST 37 diameter $25 \mathrm{~mm}$, panjang $410 \mathrm{~mm}$

- Massa unbalance dan massa overhung menggunakan piringan baja diameter $120 \mathrm{~mm}$, tebal $3 \mathrm{~mm}$, massa 760 gram. Pengaturan massa unbalance menggunakan baut dengan massa 8.61 gram ditempatkan pada lubanglubang piringan.
- Meja terbuat dari plat baja tebal $8 \mathrm{~mm}$, lebar $500 \mathrm{~mm}$, panjang $800 \mathrm{~mm}$, tinggi $700 \mathrm{~mm}$

- Pengatur putaran menggunakan inverter merk Siemens, rentang frekuensi listrik 0 s.d $50 \mathrm{~Hz}$

\subsection{Pengujian pada kondisi tanpa beban}

Pengujian dilakukan pada kondisi massa unbalance dan overhang tidak terpasang, hanya poros saja yang diputar motor seperti pada GAMBAR 3. Pada kondisi ini akan divariasikan putaran dengan cara mengatur frekuensi listrik melalui inverter pada frekuensi $10,20,30,40$, dan $50 \mathrm{~Hz}$ sehingga putaran poros akan berubah-ubah 246, 535, 818, 1102, dan 1387 RPM.



Gambar 3. Pengujian getaran kondisi tanpa beban

Hasil pengukuran amplitudo getaran kondisi tanpa beban pada bantalan A (dekat dengan motor), posisi vertikal (AV), horisontal (AH), dan aksial (AA) ditunjukan GAMBAR 4. Hasil pengukuran pada bantalan B ditunjukan GAMBAR 5.



Gambar 4. Amplitudo getaran bantalan A kondisi tanpa beban 


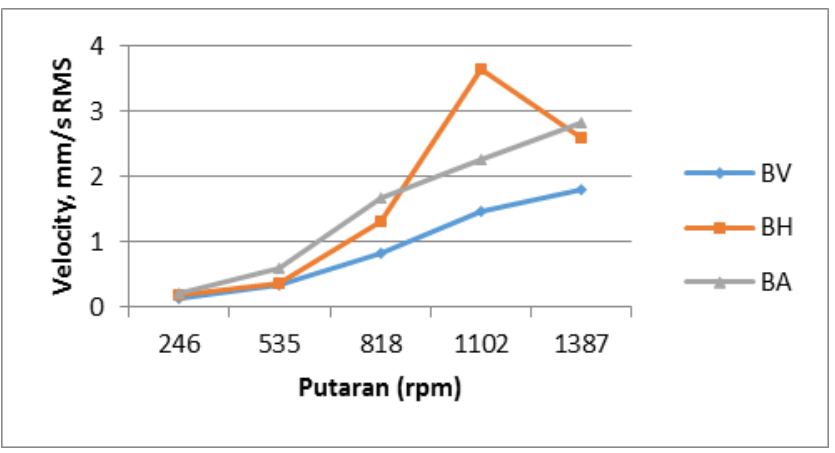

Gambar 5. Amplitudo getaran bantalan B kondisi tanpa beban

Dari GAMBAR 4 dan 5 diketahui bahwa amplitudo tertinggi pada pengukuran bantalan A adalah sebesar $3,96 \mathrm{~mm} / \mathrm{s}$ RMS, sedangkan pada bantalan B adalah sebesar 3,64 mm/s RMS dengan kecenderungan terus meningkat seiring dengan bertambahnya putaran. Mengacu kepada standar ISO 2372 (class I), amplitudo getaran pada kedua bantalan sudah masuk kategori "unsatisfactory" atau tidak memuaskan. Apabila digunakan standar ISO 10816-3 (group 2), maka amplitudo getaran tergolong "short term operation allowable" atau masih diizinkan untuk pemakaian jangka pendek.

Dari perbandingan amplitudo getaran terhadap kedua standar tersebut diketahui bahwa ada potensi/gejala kerusakan pada alat. Untuk mengetahui penyebabnya dilakukan analisis terhadap spektrum getaran.

GAMBAR 6 menunjukan analisis terhadap spektrum getaran bantalan A pada pengukuran arah horisontal pada putaran 1386 RPM $(23.1 \mathrm{~Hz})$. Dari gambar tersebut terlihat bahwa amplitudo pada spektrum getaran menimbulkan "harmonic" yaitu kelipatan bilangan bulat dari frekuensi putaran mesin, yaitu 1X (satu kali), 2X, 3X, 4X, 5X, 6X dan seterusnya. Hal ini juga bisa dilihat dari spektrum getaran bantalan $\mathrm{B}$ pada putaran yang sama seperti pada GAMBAR 7.

"Harmonic" amplitudo puncak pada spektrum getaran merupakan ciri dari "rotating looseness" atau kekendoran berputar yang diakibatkan clearance berlebih antara komponen yang berputar dan komponen yang diam. Pada mesin yang dibuat clearance berlebih diduga berasal dari keausan pada bantalan gelinding yang digunakan. Hal ini juga terlihat dari adanya amplitudo "non-synchronous" yaitu amplitudo tinggi yang bukan kelipatan bilangan bulat seperti pada $2.2 \mathrm{X}, 3.3 \mathrm{X}, 5.3 \mathrm{X}, 6.3 \mathrm{X}$ dan lain-lain. Dimana "nonsynchronous" merupakan salah satu indikasi dari kerusakan bantalan gelinding.



Gambar 6. Spektrum getaran pada bantalan A horisontal kondisi tanpa beban putaran 1387 RPM

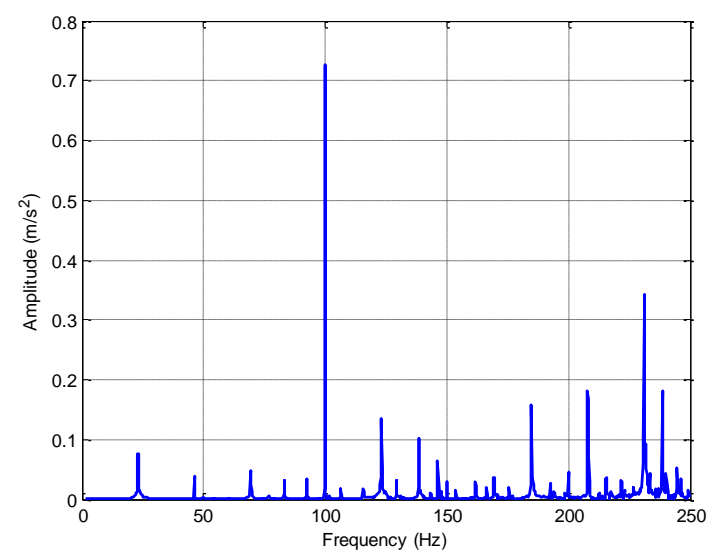

Gambar 7. Spektrum getaran pada bantalan B horisontal kondisi tanpa beban putaran 1387 RPM

\subsection{Pengujian pada kondisi beban massa unbalance}

Pengujian dilakukan dengan memasang beban piringan massa unbalance di tengah seperti GAMBAR 8. Kemudian pengaturan massa unbalance dengan menambahkan baut pada lubang-lubang piringan massa unbalance. Massa satu baut adalah 8.61 gram, pada pengujian akan divariasikan massa unbalance sampai dengan empat buah baut (34.44 gram) pada putaran tetap 1386 RPM. 




Gambar 8. Pengujian getaran kondisi beban massa unbalance

Hasil pengukuran amplitudo getaran kedua bantalan pada posisi vertikal, horisontal, dan radial ditunjukan GAMBAR 9 dan 10.

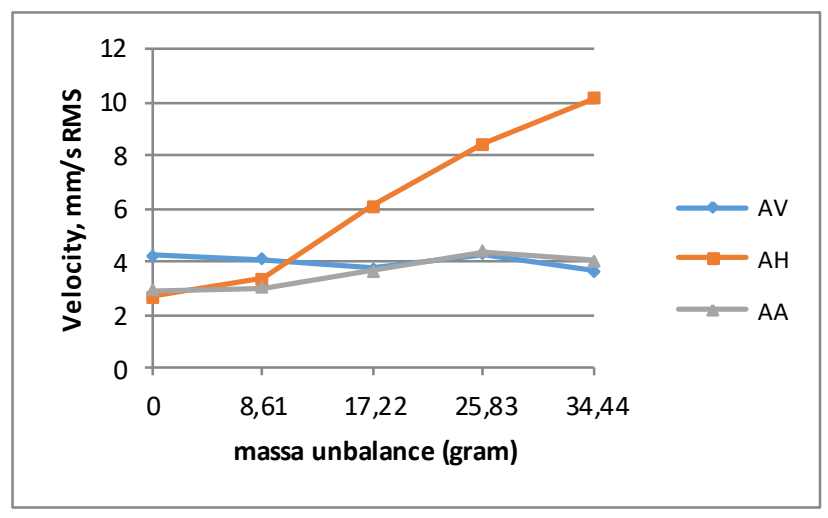

Gambar 9. Amplitudo getaran bantalan A pada kondisi beban massa unbalance

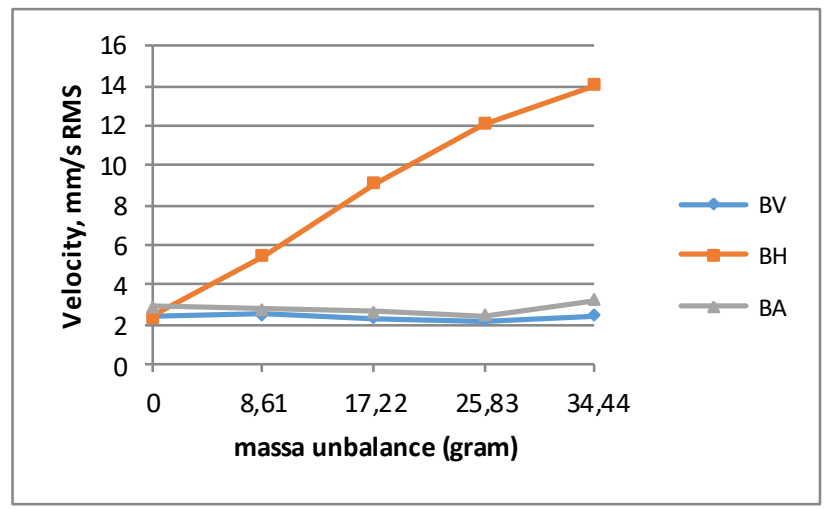

Gambar 10. Amplitudo getaran bantalan A pada kondisi beban massa unbalance
Dari GAMBAR 9 dan 10 terlihat bahwa amplitudo getaran pada arah horisontal linear dengan penambahan massa unbalance. Hal ini sesuai dengan teori bahwa gaya yang dihasilkan akibat massa unbalance berbanding lurus dengan massa unbalance, jarak massa tersebut terhadap sumbu, serta kuadrat putaran poros [4].

Amplitudo besar pada arah horisontal dikarenakan mesin yang dibuat memiliki kekakuan (stiffness) yang lebih kecil pada arah horisontal dibanding arah vertikal dan aksial, sehingga getarannya akan lebih besar pada arah horisontal.

Spektrum getaran pada rentang frekuensi sampai $100 \mathrm{~Hz}$ pada bantalan A dan B arah horisontal pada putaran 1386 RPM

$(23.1 \mathrm{hz})$ dengan variasi massa unbalance ditunjukan

GAMBAR 11 dan 12. Dari gambar terlihat ciri unbalance yaitu amplitudo besar pada $1 \mathrm{X}$ putaran mesin $(23.1 \mathrm{hz})$, yang nilainya semakin meningkat dengan bertambahnya massa unbalance.

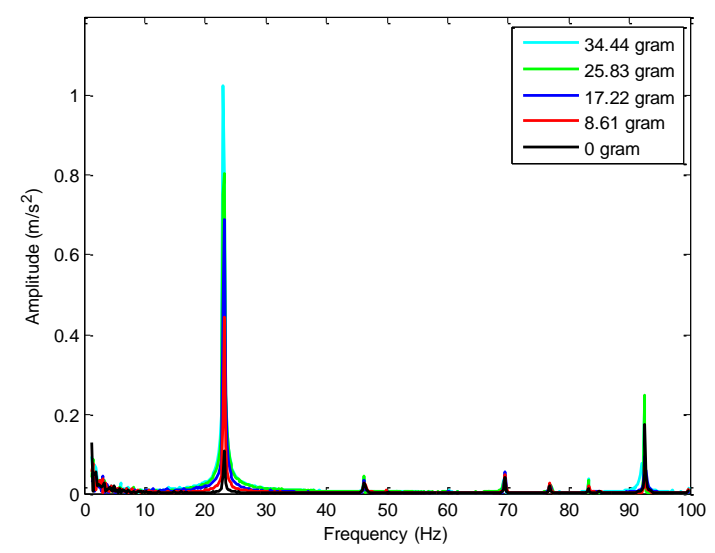

Gambar 11. Spektrum getaran bantalan A putaran 1386 RPM, dengan variasi massa unbalance

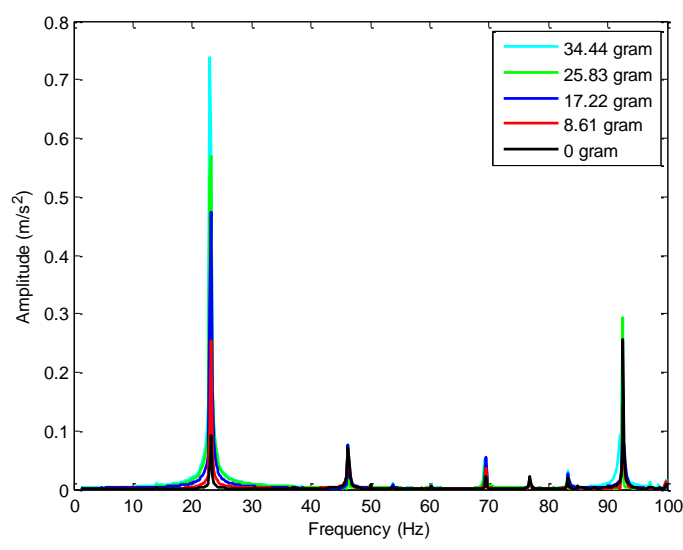

Gambar 12. Spektrum getaran bantalan B putaran 1386 RPM, dengan variasi massa unbalance 
Adapun spektrum getaran dengan rentang frekuensi sampai dengan $250 \mathrm{~Hz}$ ditunjukan GAMBAR 13 dan 14. Dari gambar terlihat bahwa 'harmonic' masih terlihat seperti pada kondisi tanpa beban. Ini menunjukan bahwa rotating looseness masih dapat dideteksi pada kondisi dibebani dengan massa unbalance. Dari gambar juga terlihat bahwa besarnya amplitudo 'harmonic' tidak terpengaruh oleh massa unbalance.

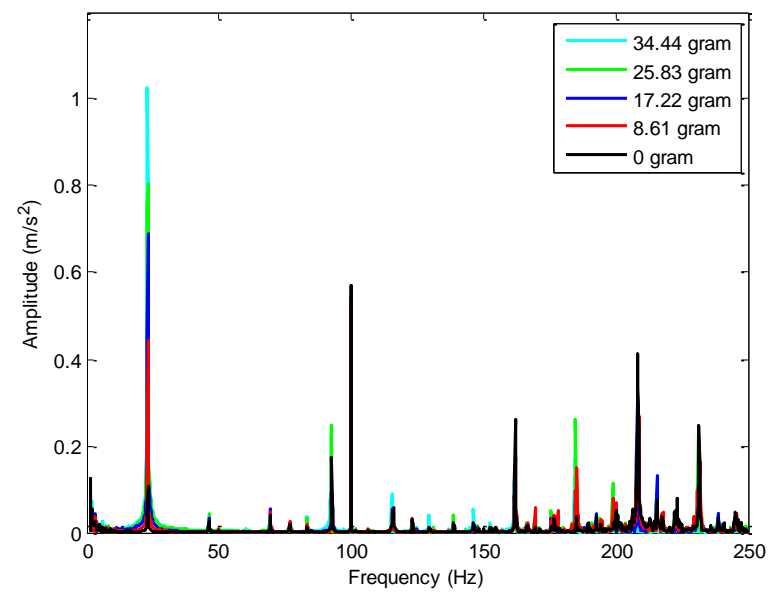

Gambar 13. Spektrum getaran bantalan A putaran 1386 RPM, dengan variasi massa unbalance sampai 250



Gambar 14. Spektrum getaran bantalan B putaran 1386 RPM, dengan variasi massa unbalance sampai $250 \mathrm{~Hz}$

\section{KESIMPULAN}

Vibration test bench yang dibuat bisa menunjukan kondisi unbalance yaitu amplitudo tinggi pada $1 \mathrm{X}$ (satu kali) putaran mesin dan nilainya sebanding dengan massa unbalance. Dari penelitian juga diketahui bahwa amplitudo getaran paling besar pada arah horisontal dimana kekakuan mesin paling kecil. Dari pengujian kondisi tanpa beban dan dengan beban unbalance muncul 'harmonic' pada spektrum getaran yang merupakan ciri 'rotating looseness', hal ini dimungkinkan diakibatkan oleh keausan bantalan. Hal lain yang diamati dari penelitian ini adalah munculnya amplitudo tinggi pada spektrum getaran yang menunjukan pengaruh medan listrik, yang nilainya $2 \mathrm{X}$ (dua kali) frekuensi jala-jala listrik.

Pada penelitian berikutnya pengukuran spektrum getaran perlu dilakukan pada arah aksial dan vertikal untuk mengetahui karakteristiknya pada arah tersebut. Pengukuran sudut fase juga perlu dilakukan sebagai parameter lain dalam analisis getaran akibat unbalance.

\section{DAFTAR PUSTAKA}

[1] Mobius Institute, 2012, Vibration Training Course Book Category I, Mobius Institute

[2] Wright P., Dornfeld D., Ota N, 2008, "Condition Monitoring in End-Milling Using Wireless Sensor Networks", Transactions of NAMRI/SME, Volume 36

[3] Yan R. \& Gao R.X, 2008, "Modal Parameter Identification from Output-only Measurement Data: Application to Operating Spindle Condition Monitoring", Proceedings of the 8th International Conference on Frontiers of Design and Manufacturing

[4] Mobley R.K, 2008, Maintenance Engineering Handbook seventh edition, Mc. Graw-Hill

[5] Wiggelinkhuizen, E., et.al, 2007, Assesment of Condition Monitoring Techniques for Offshore Wind Farm, ASME: Journal of Solar Energy Engineering Vol. 130

[6] Payant R.P., Lewis B.T., 2007, Facility Manager's Maintenance Handbook second edition, Mc. GrawHill

[7] Mevel \& Guyader, 2008, Experiments on routes to chaos in ball bearings, Journal of Sound and Vibration Volume 318, Issue 3, 9 December 2008, Pages 549-564

[8] Jinglong Chen, Yanyang Zi, Zhengjia He, Xiaodong Wang, 2013, Adaptive redundant multiwavelet denoising with improved neighboring coefficients for gearbox fault detection, Journal of Mechanical Systems and Signal Processing, Volume 38, Issue 2, 20 July 2013, Pages 549-568

[9] Ghafari S.H., 2007, A Fault Diagnosis System for Rotary Machinery Supported by Rolling Element Bearings, Doctoral Thesis University of Waterloo Canada 